\title{
Efficacy of Liposomal Bupivacaine Infiltration on the Management of Total Knee Arthroplasty
}

Bryan Sakamoto, MD, PhD; Shelly Keiser, PharmD; Russell Meldrum, MD;

Gene Harker, MD, PhD; Andrew Freese, MD

IMPORTANCE Liposomal bupivacaine is a novel extended-duration anesthetic that has recently been used for local infiltration in total knee arthroplasty (TKA). Athough liposomal bupivacaine is widely used, it is unknown if the benefits justify the cost in the veteran population at our institution.

OBJECTIVE To evaluate a change in practice: the effect of local infiltration of liposomal bupivacaine on perioperative outcomes in patients undergoing primary TKA.

DESIGN, SETTING, AND PARTICIPANTS A retrospective cohort study was conducted among patients who underwent primary TKA at a Veterans Affairs Medical Center before (March 3 , 2013-March 2, 2014) and after (March 3, 2014-March 2, 2015) the implementation of liposomal bupivacaine for local infiltration in TKA.

INTERVENTION Drug utilization evaluation of liposomal bupivacaine for local infiltration in TKA.

MAIN OUTCOMES AND MEASURES Use of opioids after discharge from the postanesthesia care unit.

RESULTS Among 199 patients, those who received liposomal bupivacaine after primary TKA (mean [SD] age, 65.3 [6.9] years; 93 males and 5 females) had a reduced median opioid use in the first 24 hours after surgery compared with those who did not receive liposomal bupivacaine (mean [SD] age, 64.9 [8.4] years; 95 males and 6 females; [intravenous morphine equivalents, 12.50 vs $22.50 \mathrm{mg} ; P=.001])$. The use of patient-controlled analgesia was also reduced among patients who received liposomal bupivacaine vs those who did not (49 vs 91; $P<.001$ ). A reduction in the use of antiemetics was observed in the first 24 hours after surgery (13 vs 34; $P=.001$ ) and in the postanesthesia care unit among those who received liposomal bupivacaine vs those who did not (4 vs $20 ; P=.001$ ). The number of patients in the postanesthesia care unit with no pain was improved among those who received liposomal bupivacaine vs those who did not ( $44 \mathrm{vs} 19 ; P<.001$ ). Although median (interquartile range) pain scores in the postanesthesia care unit were improved among patients who received liposomal bupivacaine vs those who did not (4.0 [0.0-6.6] vs 5.5 [3.0-7.5]; $P=.001$ ), patients who received liposomal bupivacaine had greater median (interquartile range) pain scores 48 hours (5.5 [4.0-7.0] vs 5.0 [3.0-6.0]; $P=.01$ ), 72 hours (5.0 [4.0-6.0] vs 4.0 [2.0-6.0]; $P=.002$ ), and 96 hours (5.0 [3.0-6.5] vs 4.0 [1.0-5.0]; $P=.003)$ after surgery than those who did not receive liposomal bupivacaine. There was no difference in the median length of stay between the 2 groups. Institutional cost savings was estimated at $\$ 27000$ per year.

CONCLUSIONS AND RELEVANCE Local infiltration of liposomal bupivacaine reduces use of opioids in the first 24 hours after primary TKA. Similarly, reduction in antiemetic use and improved postoperative pain are also seen in the first 24 hours after surgery but are limited to this time frame. Furthermore, a positive institutional cost savings was observed.

JAMA Surg. 2017;152(1):90-95. doi:10.1001/jamasurg.2016.3474

Published online October 12, 2016.
Author Affiliations: Department of Anesthesia, Richard L. Roudebush Veterans Affairs Medical Center, Indianapolis, Indiana (Sakamoto, Harker); Department of Anesthesia, Indiana University School of Medicine, Indianapolis (Sakamoto, Harker); Department of Pharmacy, Richard L. Roudebush Veterans Affairs Medical Center, Indianapolis, Indiana (Keiser); Department of Orthopedic Surgery, Richard L. Roudebush Veterans Affairs Medical Center, Indianapolis, Indiana (Meldrum, Freese); Department of Orthopedic Surgery, Indiana University School of Medicine, Indianapolis (Meldrum, Freese).

Corresponding Author: Bryan Sakamoto, MD, PhD, Department of Anesthesia, Richard L. Roudebush Veterans Affairs Medical Center, 1481 W 10 St, Indianapolis, IN 46202 (bryan.sakamoto@va.gov). 
A s the number of patients undergoing total knee arthroplasty (TKA) increases, the search for ways to improve outcomes also increases. Adequate pain control is associated with improved early mobilization and participation with physical therapy following joint replacement surgery. This mobilization leads to an overall shorter length of stay in the hospital and reduction in postoperative complications. ${ }^{1,2}$

Multimodal or balanced analgesic techniques involving the use of smaller doses of opioids in combination with nonopioid analgesic drugs are becoming increasingly popular approaches to preventing pain after surgery. ${ }^{3}$ Multimodal analgesia strategies are recognized as effective methods for improving postoperative pain management while minimizing opioid-associated adverse effects, ${ }^{4}$ which include ventilatory depression, drowsiness and sedation, postoperative nausea and vomiting, pruritus, urinary retention, ileus, and constipation, which can delay hospital discharge and lead to unanticipated hospital admissions. ${ }^{5}$ Multimodal analgesic strategies reduce these adverse effects, and, as a result, patients mobilize more quickly and are discharged from the hospital earlier. ${ }^{1,6-8}$ In addition, it has been suggested by the Joint Commission that excessive use of postoperative opioid analgesics leads to decreased patient satisfaction. ${ }^{3}$

The multimodal approach uses many delivery systems, including oral agents, epidural catheters, peripheral nerve blocks, and periarticular injection (PAI). Research suggests that PAI provides postoperative pain scores comparable with those achieved with epidural catheters and femoral nerve blocks, with a lower risk of quadriceps weakness and systemic adverse effects. ${ }^{9,10}$ These advantages of PAI allow patients to mobilize more quickly and reduce the risk of falling, leading to improved participation with therapy and patient satisfaction..$^{9,11}$

Liposomal bupivacaine is a novel formulation of bupivacaine approved by the US Food and Drug Administration for local infiltration of surgical sites to produce extended postsurgical analgesia. It has recently emerged as a popular option for PAI because its therapeutic effects last up to 72 hours. ${ }^{12,13}$ Furthermore, its use was associated with an overall decrease in use of narcotics by patients undergoing total joint arthroplasty. ${ }^{13}$ Previous studies have established the safety and efficacy of liposomal bupivacaine, and there has been no evidence of increased adverse effects or outcomes in comparison with bupivacaine hydrochloride. ${ }^{13-17}$

Several small studies have shown improved pain scores, decreased use of narcotics, and shorter length of stay following total joint arthroplasty with the use of liposomal bupivacaine PAI. ${ }^{8,11}$ Although liposomal bupivacaine is more expensive than alternative PAI agents (eg, bupivacaine and ropivacaine hydrochloride), it has recently gained favor at the Richard L. Roudebush Veterans Affairs Medical Center for TKA surgery. The main purpose of this medication use study is to evaluate the cost vs benefit of using this agent in our veteran patient population. To our knowledge, this is the first study to evaluate the use of liposomal bupivacaine in TKA in the Veterans Affairs medical system.

\section{Key Points}

Question Do the benefits justify the cost of liposomal bupivacaine for local infiltration in total knee arthroplasty in a veteran population?

Findings In a drug utilization evaluation, patients undergoing total knee arthroplasty with liposomal bupivacaine had a reduced median use of opioids in the initial 24 hours after surgery, as well as a reduction in the use of patient-controlled analgesia and antiemetics. An institutional cost savings was estimated at $\$ 27000$ per year.

Meaning The results of this drug utilization evaluation support the use of local infiltration of liposomal bupivacaine in total knee arthroplasty.

\section{Methods}

\section{Study Design}

A single-center, 2-year, retrospective cohort study was performed to evaluate the effect of PAI of liposomal bupivacaine on postoperative use of narcotics, as well as other patient clinical outcomes, in patients undergoing elective TKA. This interperiod study evaluated patient clinical outcomes before (March 3, 2013-March 2, 2014) and after (March 3, 2014-March 2, 2015) the implementation of a change in practice: the addition of PAI of liposomal bupivacaine in patients undergoing TKA. All procedures were performed by a single staff surgeon (R.M.) at the Richard L. Roudebush Veterans Affairs Medical Center. Only patients undergoing elective primary total joint arthroplasty were included. Patients who underwent a revision of prior TKA, unicompartmental knee arthroplasty, or bilateral arthroplasty and those who did not receive a femoral or adductor canal nerve block were excluded from the analysis. Other data collected included patient's age, sex, height, weight, body mass index, American Society of Anesthesiologists Risk Index scores, presence of chronic pain (use of opioids for $>3$ months), and tobacco use. The use of these data conforms with the Health Insurance Portability and Accountability Act of 1996 confidentiality requirements. In addition, because this project was a retrospective medical record review and quality improvement study, approval and informed patient consent were not required by the Indiana University Institutional Review Board and the Richard L. Roudebush Veterans Affairs Medical Center.

\section{Patients Who Received a PAI}

Using a modified version of the technique described by Guild et al, ${ }^{18} 20 \mathrm{~mL}$ of $1.3 \%$ liposomal bupivacaine (266 mg) was diluted with injectable saline to a total volume of $40 \mathrm{~mL}$. A 20 -mL syringe with a $1.2 \times 40$-mm needle was used to administer the liposomal bupivacaine solution. After negative aspiration of blood, 2 to $5 \mathrm{~mL}$ of the bupivacaine solution was injected into the superficial and deep layers of the surgical field. Injection of the superficial layer was performed by staying on the edges of the operative field working toward the middle of the surgical field. The tip of the 


\begin{tabular}{|c|c|c|c|}
\hline Characteristic & $\begin{array}{l}\text { No Liposomal } \\
\text { Bupivacaine } \\
(n=101)\end{array}$ & $\begin{array}{l}\text { Liposomal } \\
\text { Bupivacaine } \\
(n=98)\end{array}$ & $P$ Value $^{\mathrm{a}}$ \\
\hline Age, mean (SD), y & $64.9(8.4)$ & $65.3(6.9)$ & .70 \\
\hline \multicolumn{4}{|l|}{ Sex } \\
\hline Male & 95 & 93 & \multirow[t]{2}{*}{.80} \\
\hline Female & 6 & 5 & \\
\hline Weight, mean (SD), kg & $111.40(24.88)$ & $108.47(25.39)$ & .41 \\
\hline Height, mean (SD), cm & $176.60(8.10)$ & $176.48(7.40)$ & .91 \\
\hline BMI, mean (SD) & $35.74(7.68)$ & $34.50(7.07)$ & .24 \\
\hline \multicolumn{4}{|l|}{ ASA Risk Index score } \\
\hline 2 & 1 & 8 & \multirow{2}{*}{$.02^{\mathrm{b}}$} \\
\hline 3 & 100 & 90 & \\
\hline \multicolumn{4}{|l|}{$\begin{array}{l}\text { Chronic pain } \\
\text { (opioids >3 mo) }\end{array}$} \\
\hline Yes & 46 & 40 & \multirow{2}{*}{.50} \\
\hline No & 55 & 58 & \\
\hline \multicolumn{4}{|l|}{ Tobacco use } \\
\hline Yes & 29 & 24 & \multirow{2}{*}{.50} \\
\hline No & 72 & 74 & \\
\hline
\end{tabular}

Abbreviations: ASA, American Society of Anesthesiologists; BMI, body mass index (calculated as weight in kilograms divided by height in meters squared).

${ }^{a}$ Age, weight, height, and BMI are compared using $t$ test. Sex, ASA Risk Index score, chronic pain, and tobacco use are compared using $\chi^{2}$ test. All $P$ values are 2-tailed.

b Statistically significant.

needle was placed deep to the muscle's fascial layers during these injections. In the deep layer, the bupivacaine solution was injected into the extracapsular space through the deep posterior knee capsule and into the popliteal fossa. The tip of the needle was placed through the capsule until resistance was lost. The superficial and deep injections of the knee were performed before cementing of the implants.

\section{Pain Control Regimen}

Patients undergoing TKA were prescribed the following standard pain control regimen: oral hydrocodone bitartrate, $5 \mathrm{mg}$, with acetaminophen, $325 \mathrm{mg}$, or oxycodone hydrochloride, $5 \mathrm{mg}$, with acetaminophen, $325 \mathrm{mg}$, every 4 hours with an additional tablet every 4 hours as needed. For pain that could not be controlled by oral opiates, the patients were additionally offered intravenous morphine sulfate, 2 to $4 \mathrm{mg}$, or hydromorphone hydrochloride 0.5 to 1.0 mg every 4 hours as needed. For the first 24 hours, morphine or hydromorphone patientcontrolled analgesia (PCA) was offered for pain that could not be controlled by oral and intravenous opiates (at the beginning of the study period, PCA was scheduled as part of the routine admitting orders, but after the change in practice, they were ordered on an as-needed basis because patients were no longer routinely using them). Before surgery, if a patient was taking long-acting oral opiates, these medications were resumed as needed for breakthrough pain as described above. Intravenous ketorolac tromethamine, $15 \mathrm{mg}$, every 6 hours was also prescribed if renal function was within normal limits (owing to a national drug shortage, ketorolac was unavailable for 1 year that overlapped both arms of this study). On admission, home pain medications were also resumed, which could include multimodal options such as gabapentin and pregabalin. Oral hydroxyzine pamoate, $25 \mathrm{mg}$, every 6 hours as needed was available for itching and/or pain.

\section{Outcome Measures}

The primary outcome was opioid use (intravenous morphine equivalents) after discharge from the postanesthesia care unit (PACU). Secondary outcomes included perioperative and PACU opioid use, average postoperative pain scores in the PACU and surgical ward (numeric rating scale from 0 to 10), use of PCA, use of naloxone in the PACU and surgical ward, use of antiemetic medications in the PACU and surgical ward, and days to discharge. A cost analysis was completed comparing the use of liposomal bupivacaine with the institution's standard postoperative pain regimen before this change in practice.

\section{Statistical Analysis}

Continuous variables are reported as mean (SD) and analyzed using a 2-tailed $t$ test. Categorical data are compared using a $\mathrm{X}^{2}$ test and relative risk analysis. Pain scores, use of opioids, and length of stay are reported as medians. The 25th and 75th percentiles are included as indicators of variability (interquartile range). Differences in pain scores, use of opioids, and length of stay were tested using the Mann-Whitney test. $P<.05$ was considered significant. Statistical analysis was performed using SPSS, version 22 (IBM Corp).

\section{Results}

A total of 217 patients who had an elective primary TKA were studied (101 patients before the change in practice and 98 patients after the change in practice; 18 patients were excluded). Analysis of the demographic data (Table1) shows that the 2 groups are well matched except for American Society of Anesthesiologists Risk Index scores $(P=.02)$.

Patients undergoing primary TKA after the change in practice (use of liposomal bupivacaine) had a reduced median opioid use (intravenous morphine equivalents) in the first 24 hours after surgery compared with those who underwent TKA before the change in practice ( 12.50 vs $22.50 \mathrm{mg} ; P=.001$ ). No difference in median opioid use was observed in the 48 and 96 hours following surgery. However, there was an increase in median opioid use 72 hours after surgery among patients who received liposomal bupivacaine vs those who did not (20.00 vs 15.00 mg; $P$ = .003; Table 2). Although there was no difference in perioperative use of fentanyl between the 2 groups, median perioperative use of opioids was significantly reduced in the liposomal bupivacaine group (5.33 mg) compared with those who did not receive liposomal bupivacaine $(6.67 \mathrm{mg}$ ), as was median use of opioids in the PACU (2.67 vs $6.00 \mathrm{mg}$; Table 3). No naloxone was administered in either group in the PACU. In addition, there was no statistical difference in naloxone administration on the surgical ward between the 2 groups (Table 4 ).

Although median verbal pain scores in the PACU were improved in the liposomal bupivacaine group vs those who did not receive liposomal bupivacaine (4.0 vs $5.5 ; P=.001$ ) (Table 3 ), 


\begin{tabular}{|c|c|c|c|c|c|}
\hline Characteristic & $\begin{array}{l}\text { No Liposomal } \\
\text { Bupivacaine }\end{array}$ & $\begin{array}{l}\text { Patients, } \\
\text { No. }{ }^{a}\end{array}$ & $\begin{array}{l}\text { Liposomal } \\
\text { Bupivacaine }\end{array}$ & $\begin{array}{l}\text { Patients, } \\
\text { No. }{ }^{a}\end{array}$ & $P$ Value $^{\mathrm{b}}$ \\
\hline \multicolumn{6}{|c|}{ Total opioids, median (IQR), $\mathrm{h}^{\mathrm{c}}$} \\
\hline 24 & $22.50(12.25-36.00)$ & 101 & $12.50(7.50-29.48)$ & 98 & $.001^{\mathrm{d}}$ \\
\hline 48 & $24.00(18.70-29.00)$ & 101 & $25.00(20.00-32.63)$ & 98 & .07 \\
\hline 72 & $15.00(12.50-22.88)$ & 92 & $20.00(15.00-30.50)$ & 91 & $.003^{\mathrm{d}}$ \\
\hline 96 & $15.00(10.00-20.00)$ & 43 & $15.00(10.00-25.10)$ & 46 & .97 \\
\hline \multicolumn{6}{|c|}{ Pain scores, median (IQR), $\mathrm{h}$} \\
\hline 24 & $5.0(3.0-6.0)$ & 101 & $4.0(2.8-6.0)$ & 98 & .46 \\
\hline 48 & $5.0(3.0-6.0)$ & 101 & $5.5(4.0-7.0)$ & 98 & $.01^{\mathrm{d}}$ \\
\hline 72 & $4.0(2.0-6.0)$ & 92 & $5.0(4.0-6.0)$ & 91 & $.002^{\mathrm{d}}$ \\
\hline 96 & $4.0(1.0-5.0)$ & 43 & $5.0(3.0-6.5)$ & 45 & $.003^{d}$ \\
\hline LOS, median (IQR), d & $3.0(3.0-4.0)$ & 101 & $3.0(3.0-4.0)$ & 98 & .80 \\
\hline
\end{tabular}

Table 3. Perioperative and PACU Data

\begin{tabular}{|c|c|c|c|}
\hline Characteristic & $\begin{array}{l}\text { No Liposomal } \\
\text { Bupivacaine } \\
(n=101)\end{array}$ & $\begin{array}{l}\text { Liposomal } \\
\text { Bupivacaine } \\
(\mathrm{n}=98)\end{array}$ & $P$ Value $^{\mathrm{a}}$ \\
\hline \multicolumn{4}{|c|}{ Perioperative medication use, median (IQR) } \\
\hline Fentanyl $^{\mathrm{b}}$ & $25(15-25)$ & $25(15-25)$ & .97 \\
\hline Opioids $^{c}$ & $6.67(4.00-9.33)$ & $5.33(2.67-6.67)$ & $.01^{\mathrm{d}}$ \\
\hline \multicolumn{4}{|c|}{ PACU medication use, median (IQR) } \\
\hline Opioids ${ }^{c}$ & $6.00(2.34-9.33)$ & $2.67(0.00-6.67)$ & $<.001^{\mathrm{d}}$ \\
\hline \multicolumn{4}{|l|}{ Antiemetic use, No. } \\
\hline Yes & 20 & 4 & \multirow{2}{*}{$.001^{\mathrm{d}}$} \\
\hline No & 81 & 94 & \\
\hline Pain score, median (IQR) & $5.5(3.0-7.5)$ & $4.0(0.0-6.6)$ & $.001^{\mathrm{d}}$ \\
\hline \multicolumn{4}{|l|}{ Patients with no pain, No. } \\
\hline Yes & 19 & 44 & \multirow{2}{*}{$<.001^{d}$} \\
\hline No & 82 & 54 & \\
\hline
\end{tabular}

Abbreviations: IQR, interquartile range; LOS, length of stay.

a Numbers in the Total opioids and Pain scores groups decrease as patients are discharged.

${ }^{\mathrm{b}}$ Differences in total opioids, pain scores, and LOS were analyzed using the Mann-Whitney test. All $P$ values are 2-tailed.

c Total opioid use presented in intravenous morphine equivalents. d Statistically significant.
Table 4. Antiemetic and Use of Patient-Controlled Analgesia

\begin{tabular}{|c|c|c|c|c|c|}
\hline \multirow[b]{2}{*}{ Characteristic } & \multicolumn{2}{|c|}{$\begin{array}{l}\text { No Liposomal } \\
\text { Bupivacaine }\end{array}$} & \multicolumn{2}{|c|}{$\begin{array}{l}\text { Liposomal } \\
\text { Bupivacaine }\end{array}$} & \multirow[b]{2}{*}{$P$ Value $^{\mathrm{a}}$} \\
\hline & Yes & No & Yes & No & \\
\hline \multicolumn{6}{|l|}{$\begin{array}{l}\text { Patients receiving } \\
\text { antiemetics, } \mathrm{h}^{\mathrm{b}}\end{array}$} \\
\hline 24 & 34 & 67 & 13 & 85 & $.001^{\mathrm{c}}$ \\
\hline 48 & 21 & 80 & 13 & 85 & .16 \\
\hline 72 & 4 & 97 & 5 & 86 & .62 \\
\hline 96 & 0 & 43 & 3 & 43 & .09 \\
\hline Use of naloxone & 1 & 100 & 0 & 98 & .32 \\
\hline $\begin{array}{l}\text { Patient-controlled } \\
\text { analgesia }\end{array}$ & 91 & 10 & 49 & 49 & $<.001^{\mathrm{c}}$ \\
\hline
\end{tabular}

a Differences in antiemetic, naloxone, and patient-controlled analgesia use were analyzed using the $\chi^{2}$ test. All $P$ values are 2 -tailed.

${ }^{\mathrm{b}}$ The number in the patients receiving antiemetics group decreases as patients are discharged.

c Statistically significant.

those who received liposomal bupivacaine had greater median pain scores 48 (5.5 vs 5.0; $P=.01$ ), 72 (5.0 vs 4.0; $P=.002$ ), and 96 (5.0 vs 4.0; $P=.003$ ) hours after surgery (Table 2 ). The number of patients with no pain in the PACU was improved in the liposomal bupivacaine group vs those who did not receive liposomal bupivacaine (44 vs 19; $P<.001$; absolute relative risk [ARR], 0.26; 95\% CI, 0.25-0.27) (Table 3 and Table 5). There was a $139 \%$ relative risk reduction of patients having pain in the PACU when treated with liposomal bupivacaine (Table 5). The number needed to treat was 3.8 (95\% CI, 3.7-4.0), indicating that for every 3.8 patients treated with liposomal bupivacaine, 1 patient will have no pain in the PACU (Table 5).

A reduction in antiemetic use in the liposomal bupivacaine group vs those who did not receive liposomal bupivacaine was observed in the first 24 hours after surgery (13 vs 34; $P=.001$; ARR, 0.20; 95\% CI, 0.16-0.24) (Tables 4 and 5) and in the PACU ( 4 vs 20; $P=.001$; ARR, 0.16; 95\% CI, 0.160.16) (Tables 3 and 5). There was a $61 \%$ and $72 \%$ relative risk reduction of patients requiring an antiemetic in the first 24 hours after surgery and in the PACU when treated with liposomal bupivacaine, respectively (Table 5 ). The number needed to treat was 5.0 (95\% CI, 4.2-6.3) and 6.4 (95\% CI, 6.4-6.4), indicating that for every 5.0 and 6.4 patients treated with liposomal bupivacaine, 1 patient will require an antiemetic in the first 24 hours after surgery and in the PACU, respectively (Table 5). The use of PCA was reduced in the liposomal bupivacaine group vs those who did not receive liposomal bupivacaine (49 vs 91; $P<.001$; ARR, 0.40; 95\% CI, 0.39-0.41) (Tables 4 and 5). There was a 45\% relative risk reduction of patients requiring PCA when treated with liposomal bupivacaine (Table 5). The number needed to treat was 2.5 (95\% CI, 2.4-2.6), indicating that for every 2.5 patients treated with liposomal bupivacaine, 1 patient will require PCA (Table 5). There was no difference in the median length of stay between the 2 groups (Table 2). 


\begin{tabular}{llll}
\hline Table 5. Relative Risk & & & \\
\hline Characteristic & $\begin{array}{l}\text { Absolute RR } \\
(95 \% \mathrm{Cl})\end{array}$ & $\begin{array}{l}\text { RR } \\
\text { Reduction }\end{array}$ & $\begin{array}{l}\text { NNT } \\
(95 \% \mathrm{Cl})\end{array}$ \\
\hline $\begin{array}{l}\text { RR of receiving an antiemetic with liposomal bupivacaine } \\
\text { in first 24 h after surgery }\end{array}$ & $0.20(0.16-0.24)$ & 0.61 & $5.0(4.2-6.3)$ \\
$\begin{array}{l}\text { RR of receiving an antiemetic in the PACU } \\
\text { with liposomal bupivacaine }\end{array}$ & $0.16(0.16-0.16)$ & 0.72 & $6.4(6.4-6.4)$ \\
\hline RR of receiving PCA with liposomal bupivacaine & $0.40(0.39-0.41)$ & 0.45 & $2.5(2.4-2.6)$ \\
\hline RR of no pain in the PACU with liposomal bupivacaine & $0.26(0.25-0.27)$ & 1.39 & $3.8(3.7-4.0)$ \\
\hline
\end{tabular}

Abbreviations: NNT, number needed to treat; PACU, postanesthesia care unit; PCA, patient-controlled analgesia; $\mathrm{RR}$, relative risk.

\section{Discussion}

Significant differences were found in both the primary and secondary outcomes in patients who received liposomal bupivacaine for TKA. Total opioid use was decreased for up to 24 hours after surgery, resulting in nearly a 50\% decrease in use of PCA. In addition, perioperative and PACU opioid use was significantly reduced in the liposomal bupivacaine group. Patients' pain was often adequately controlled with use of oral opioids. Secondarily, use of antiemetic medication significantly decreased in the first 24 hours after surgery in patients in the PACU and the surgical ward. These results appear to contradict those of Bagsby et al, ${ }^{19}$ who reported no significant difference in mean use of opioids and antiemetics. They reported that, in the first 24 hours after surgery, mean (SD) opioid use (in morphine equivalents) for those in the liposomal bupivacaine group ( $n=65$ ) was 6.21 (18.30) $\mathrm{mEq}$ and for those in the ropivacaine group $(\mathrm{n}=85)$ was $13.75(13.42) \mathrm{mEq}(P=.34)$. Using the provided values in their article, we calculated $P=.004$ using a 2-tailed $t$ test, indicating that the liposomal bupivacaine treatment group used significantly less opioids in the first 24 hours after surgery than did the ropivacaine group.

A reduction in use of opioids decreases the potential for adverse events such as sedation, respiratory depression, nausea, vomiting, and constipation. Our study shows a significant decrease in use of opioids, particularly of intravenous opioids, in the first 24 hours after surgery among those who received liposomal bupivacaine, which translates into increased patient safety. One patient in the control group received naloxone for sedation reversal vs no patients in the liposomal bupivacaine group. This result, although not statistically significant, might be deemed clinically significant. Furthermore, our study demonstrates a decrease in use of antiemetics, which equates to less nausea and vomiting and presumably greater patient satisfaction.

We also observed that significantly more patients in the liposomal bupivacaine cohort reported no pain in the PACU, which coincides with results from a study by Barrington et al, ${ }^{8}$ who reported that a higher percentage of patients who received liposomal bupivacaine reported no pain during their hospital stay. Pain scores in our study were also lower among patients in the PACU; however, this finding was not sustained once patients were moved to a bed on the surgical ward. In addition, there was no statistical difference in median opioid use between the 2 groups at 48 and 96 hours after surgery. However, there was a statistically significant increase in median opioid use 72 hours after surgery in the liposomal bupivacaine group (Table 2). Although these effects may be secondary to a rebound effect of the liposomal bupivacaine injection, it may also suggest limited utility of this technique.

Multiple studies report a decreased length of stay for patients who received liposomal bupivacaine. ${ }^{20-22}$ Broome and Burnikel ${ }^{21}$ noted that $12 \%$ of patients who received liposomal bupivacaine were discharged on postoperative day 1 vs none of the patients who received a femoral nerve block. Berend et $\mathrm{al}^{22}$ reported that more than $98 \%$ of patients were discharged on postoperative day 0 and had a decreased time in the PACU. In our study, data on patients' readiness for discharge from the PACU were not collected since nurses only documented when the patient was discharged from our PACU. At our institution, for a variety of reasons, a patient may remain in the PACU despite clinically being ready for discharge (eg, no bed available and shift change on the wards). Our study did not show a statistically significant decrease in length of stay. However, many of our surgical patients are referred to this facility from other facilities, and their discharge to home or a rehabilitation facility is dependent on nonmedical issues, such as availability of transportation and family to help in their care.

Although the intermediate and long-term benefits of liposomal bupivacaine were not specifically addressed in our study, a large retrospective cohort study found that opioidsparing regimens may decrease the frequency of opioidassociated adverse drug events, particularly among high-risk patients ( $\geq 65$ years, males, obesity, prior opioid use, and higher Charlson Comorbidity Indexes), thereby decreasing overall cost burden to the hospital system and improving patient outcomes. ${ }^{23}$ In our study, the short-term benefits of PAI included a significant decrease in opioid consumption 24 hours after surgery, reduction in use of PCA, and less use of antiemetics. Reduction in use of opioids has been shown to increase patient satisfaction ${ }^{3}$ and safety secondary to a decrease in opioid-associated adverse events. ${ }^{5}$

Our study found a decrease in total per-patient cost based on use of PCA. In the patients who did not receive PCA, there was a cost savings of approximately $\$ 350$ per patient (PCA pump, medication, and carbon dioxide tubing and monitoring, minus the cost of the medication). Based on the number needed to treat of 2.5 (Table 5), use of liposomal bupivacaine will result in a savings of approximately $\$ 15000$ per year based on the number of patients in this study. (Our institutional cost of liposomal bupivacaine was recently reduced by $50 \%$, which would change the cost savings to approximately $\$ 500$ per patient who did not receive PCA or $\$ 27000$ per year). 
This study has several limitations, including retrospective design, lack of standardization of recording pain scores, and variations in postoperative adjunctive pain medications (ketorolac, celecoxib, acetaminophen, and ibuprofen). In addition, once the change in practice occurred, all patients still received PCA until the nurses were informed of the change, at which point PCA was prescribed on an as-needed basis. This delay in change probably led to additional PCA given to patients in the liposomal bupivacaine group and underestimated the true cost savings.

\section{Conclusions}

The results of this drug utilization evaluation support the use of local infiltration of liposomal bupivacaine in primary TKA surgery at this institution. Specifically, there was a reduction in use of opioids in the first 24 hours and the need for PCA after surgery. In addition, use of antiemetics decreased and postoperative pain improved in the first 24 hours after surgery. Finally, a positive institutional cost savings was appreciated.

\section{ARTICLE INFORMATION}

Accepted for Publication: June 20, 2016.

Published Online: October 12, 2016.

doi:10.1001/jamasurg.2016.3474

Authors Contributions: Drs Sakamoto and Meldrum had full access to all the data in the study and take responsibility for the integrity of the data and the accuracy of the data analysis.

Study concept and design: Sakamoto, Keiser, Meldrum.

Acquisition, analysis, or interpretation of data: All authors.

Drafting of the manuscript: Sakamoto, Keiser,

Freese.

Critical revision of the manuscript for important

intellectual content: All authors.

Statistical analysis: Sakamoto.

Administrative, technical, or material support: All authors.

Study supervision: Sakamoto, Keiser, Harker.

Conflict of Interest Disclosures: None reported.

Funding/Support: This material is the result of work supported with resources and the use of facilities at the Richard L. Roudebush Veterans Affairs Medical Center, Indianapolis, Indiana.

Role of the Funder/Sponsor: The funding source had no role in the design and conduct of the study collection, management, analysis, and interpretation of the data; preparation, review, or approval of the manuscript; and decision to submit the manuscript for publication.

Disclaimer: The contents of this article do not represent the views of the US Department of Veterans Affairs or the US government.

Previous Presentation: This study was presented at the 2016 Association of VA Surgeons Annual Meeting; April 12, 2016; Virgina Beach, Virginia.

Additional Contributions: Kenneth Gwirtz, MD, Department of Anesthesia, Richard L. Roudebush Veterans Affairs Medical Center, provided editorial comments. He was not compensated for his contribution. Angie Plummer, LPN, CCRP, Department of Anesthesia, Indiana University, provided clerical assistance. She was compensated for her contribution.

\section{REFERENCES}

1. Peters CL, Shirley B, Erickson J. The effect of a new multimodal perioperative anesthetic regimen on postoperative pain, side effects, rehabilitation, and length of hospital stay after total joint arthroplasty. J Arthroplasty. 2006;21(6)(suppl 2): 132-138.
2. Capdevila X, Barthelet $Y$, Biboulet P, Ryckwaert Y, Rubenovitch J, d'Athis F. Effects of perioperative analgesic technique on the surgical outcome and duration of rehabilitation after major knee surgery. Anesthesiology. 1999;91(1):8-15.

3. White PF. The changing role of non-opioid analgesic techniques in the management of postoperative pain. Anesth Analg. 2005;101(5) (suppl):S5-S22.

4. Elvir-Lazo OL, White PF. The role of multimodal analgesia in pain management after ambulatory surgery. Curr Opin Anaesthesiol. 2010;23(6):697-703.

5. White PF. The role of non-opioid analgesic techniques in the management of pain after ambulatory surgery. Anesth Analg. 2002;94(3): 577-585.

6. Kehlet $\mathrm{H}$, Wilmore DW. Multimodal strategies to improve surgical outcome. Am J Surg. 2002;183(6): 630-641.

7. Dorr LD, Raya J, Long WT, Boutary M, Sirianni LE. Multimodal analgesia without parenteral narcotics for total knee arthroplasty. J Arthroplasty. 2008;23 (4):502-508.

8. Barrington JW, Olugbode O, Lovald S, Ong K, Watson H, Emerson RH Jr. Liposomal bupivacaine: a comparative study of more than 1000 total joint arthroplasty cases. Orthop Clin North Am. 2015; 46(4):469-477.

9. Meftah M, Wong AC, Nawabi DH, Yun RJ, Ranawat AS, Ranawat CS. Pain management after total knee arthroplasty using a multimodal approach. Orthopedics. 2012;35(5):e660-e664.

10. Heim EA, Grier AJ, Butler RJ, Bushmiaer M, Queen RM, Barnes CL. Use of liposomal bupivacaine instead of an epidural can improve outcomes following total knee arthroplasty. J Surg Orthop Adv. 2015;24(4):230-234.

11. Domb BG, Gupta A, Hammarstedt JE, Stake CE, Sharp K, Redmond JM. The effect of liposomal bupivacaine injection during total hip arthroplasty: a controlled cohort study. BMC Musculoskelet Disord. 2014;15:310.

12. Exparel [package insert]. San Diego, CA: Pacira Pharmaceuticals Inc; 2014.

13. Bramlett K, Onel E, Viscusi ER, Jones K. A randomized, double-blind, dose-ranging study comparing wound infiltration of DepoFoam bupivacaine, an extended-release liposomal bupivacaine, to bupivacaine $\mathrm{HCl}$ for postsurgical analgesia in total knee arthroplasty. Knee. 2012;19 (5):530-536.
14. Hu D, Onel E, Singla N, Kramer WG, Hadzic A. Pharmacokinetic profile of liposome bupivacaine injection following a single administration at the surgical site. Clin Drug Investig. 2013;33(2):109-115.

15. Tong YC, Kaye AD, Urman RD. Liposomal bupivacaine and clinical outcomes. Best Pract Res Clin Anaesthesiol. 2014;28(1):15-27.

16. Viscusi ER, Sinatra R, Onel E, Ramamoorthy SL. The safety of liposome bupivacaine, a novel local analgesic formulation. Clin J Pain. 2014;30(2) 102-110.

17. Dasta J, Ramamoorthy S, Patou G, Sinatra R. Bupivacaine liposome injectable suspension compared with bupivacaine $\mathrm{HCl}$ for the reduction of opioid burden in the postsurgical setting. Curr Med Res Opin. 2012;28(10):1609-1615.

18. Guild GN III, Galindo RP, Marino J, Cushner FD, Scuderi GR. Periarticular regional analgesia in total knee arthroplasty: a review of the neuroanatomy and injection technique. Orthop Clin North Am. 2015;46(1):1-8.

19. Bagsby DT, Ireland PH, Meneghini RM. Liposomal bupivacaine versus traditional periarticular injection for pain control after total knee arthroplasty. J Arthroplasty. 2014;29(8): 1687-1690.

20. Surdam JW, Licini DJ, Baynes NT, Arce BR. The use of Exparel (liposomal bupivacaine) to manage postoperative pain in unilateral total knee arthroplasty patients. J Arthroplasty. 2015;30(2): 325-329.

21. Broome CB, Burnikel B. Novel strategies to improve early outcomes following total knee arthroplasty: a case control study of intraarticular injection versus femoral nerve block. Int Orthop. 2014;38(10):2087-2089.

22. Berend ME, Berend KR, Lombardi AV Jr. Advances in pain management: game changers in knee arthroplasty. Bone Joint J. 2014;96-B(11)(suppl A):7-9.

23. Kessler ER, Shah M, Gruschkus SK, Raju A Cost and quality implications of opioid-based postsurgical pain control using administrative claims data from a large health system: opioid-related adverse events and their impact on clinical and economic outcomes. Pharmacotherapy. 2013;33(4):383-391. 